\title{
Implementation of Thin Walled Steel Sections
}

\author{
S. J. Mohan, S. Thendral, A. Arunya, R. Chitra
}

\begin{abstract}
Metallic flimsy sheets are twisted as basic segment to use in the use of numerous mechanical and private structures. These areas which are utilized in the structural building applications are called slight walled segments. They are made out utilizing press break machines or by rolling. The material thickness shifts from $0.20 \mathrm{~mm}$ to $8.00 \mathrm{~mm}$. Powerful propelled machines are likewise accessible to make cold framed segments up to $12 \mathrm{~mm}$. thickness.
\end{abstract}

Keywords: break machines, propelled machines, Metallic flimsy sheets

\section{INTRODUCTION}

\section{A. General}

Metallic thin sheets are bent in the form of structural section to use in the application of many industrial and residential buildings. These sections which are used in the civil engineering applications are called thin walled sections. They are made out using press break machines or by rolling. The material thickness varies from $0.20 \mathrm{~mm}$ to $8.00 \mathrm{~mm}$. High powered advanced machines are also available to make cold formed sections up to $12 \mathrm{~mm}$ thickness. [1]-[5]

\section{B. Advantages Of Cold Formed Sections}

1. They have very high strength to weight ratio.

2. Choice of the sectional geometry is left to the designers.

3. Any intricate shapes are possible to get architectural appearance of the structures.

4. Galvanising and powder coating on metals have very good advantage on corrosion protection and in elegance of the buildings.
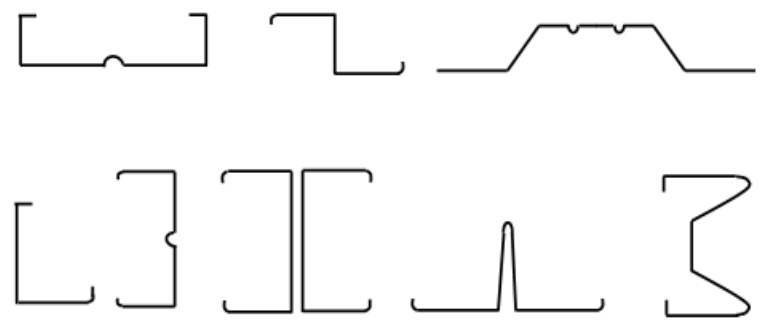

Fig 1: Commonly used cold formed steel

Revised Manuscript Received on December 11, 2019

S. J. Mohan, Assistant Professor, Department Of Civil Engineering,,Bharath Institution of Higher Education And Research,TamilNadu, India Email mohansjm@yahoo.com

S. Thendral, Assistant Professor,,Department of Civil Engineering,,Bharath Institution Of Higher Education And Research,TamilNadu, India .Email: thendral.cs@gmail.com

A.Arunya, Asistant Professor, Department Of Civil Engineering,.Bharath Institution of Higher Education And Research,TamilNadu, India Email: arunyaaaa@gmail.com

R. Chitra, Asistant Professor, Department Of Civil Engineering,,Bharath Institution of Higher Education And Research,TamilNadu, India Email: chitraroopauma@gmail.com

5. Concentration of metal away from C.G makes the section to develop more torsional rigidity which are useful for buckling consideration.

\section{Unstiffened and Stiffened elements:}

The plate elements which are supported continuously on only one edge are called unstiffened elements and those which are supported continuously on both edges are called stiffened elements. Fig. 2 shows examples of stiffened and unstiffened elements in thin walled sections commonly used. In case the unsupported part of the plate element are too wide the for the strengthening purposes an intermediate stiffeners are also provided as shown in the Fig.2 [6]-[8]
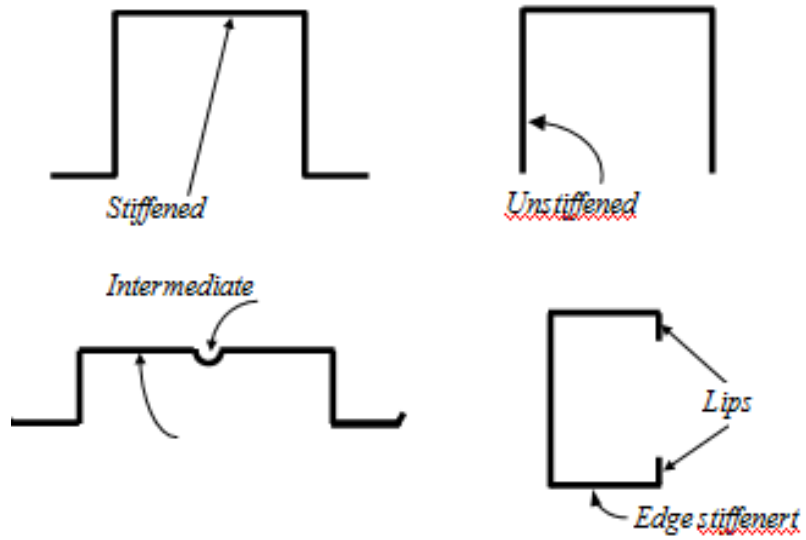

Fig. 2 Typical Stiffened and Un stiffened elements

\section{Plate Buckling:}

When the compression load acts on a plate element in its own plane then it can buckle depending on its geometric parameters and boundary conditions. Such buckling stress need not be equal to the yield strength of the material. These types of failures are called plate buckling. Plate buckling is also called as local buckling and is governed by plate buckling equation as mentioned in theory of plates.

$p_{c r}=\frac{K \pi^{2} E}{12\left(1-v^{2}\right)}\left(\frac{t}{b}\right)^{2}$

For the values for $\pi, v=0.3$ and $E=205 \mathrm{kN} / \mathrm{mm}^{2}$, we get the value of $p_{c r}$ as

$$
p_{c r} \approx 185 \times 10^{3} \times K\left(\frac{t}{b}\right)^{2} \mathrm{~V} / \mathrm{mm}^{2}
$$

The value of $K$ is dependent on support conditions and varies from 0.425 to 4.0

\section{RESULTS}

Post - buckling behaviour 


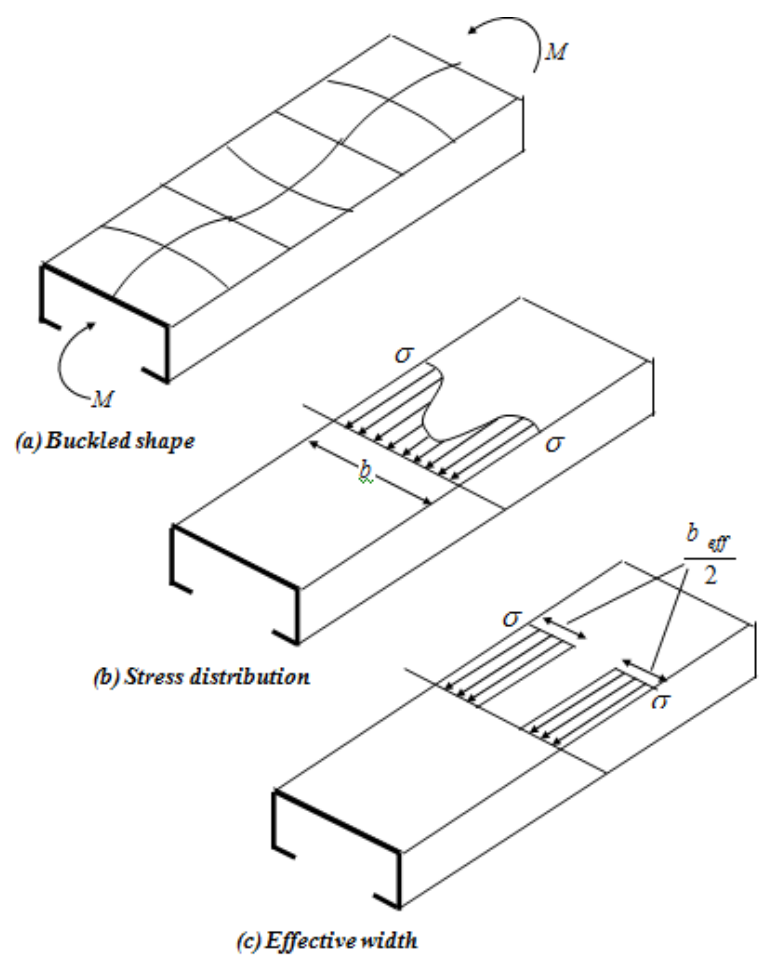

Fig. 3 Post Buckling behaviour

The phenomenon of retaining the load even after buckling load is called the post buckling behaviour of plate. When the plate deform in half sine wave curve the longitudinal fibres retain the load and resist to develop second half sine wave without failure. If the plate is restrained continuously the stress distribution also vary across section with high intensity at the edges and low intensity at other places. All the above details are marked and shown in the Fig. 3. [9]-[10]

\section{The concept of Effective}

The stress variations across the cross section is idealised as a uniform stress distribution over a width is called the effective width.

\section{IS Code 801: 1975}

With the same notation followed in the code of practice the effective width is given by

When $f_{c}>0.123 p_{c r}$, then

$$
\begin{aligned}
& \frac{b_{\text {dff }}}{b}=\left[1+14\left\{\left[\frac{f_{c}}{p_{c r}}\right]^{0.5}-0.35\right\}^{4}\right]^{-0.2} \\
& \text { 1. Example Channel with lip. }
\end{aligned}
$$

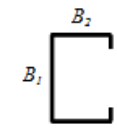

$$
K_{1}=7-\frac{1.8 h}{0.15+h}-1.43 h^{3}
$$

where $h=B_{2} / B_{1}$

\section{2) Plain channel (without lips)}

The buckling coefficient $K_{l}$ for the element of width $B_{l}$ is given by

$$
K_{1}=\frac{2}{\left(1+15 h^{3}\right)^{0.5}}+\frac{2+4.8 h}{\left(1+15 h^{3}\right)}
$$

piffeners at intermediate location

$$
\begin{aligned}
& I_{\min }=0.2 t^{4} \cdot\left(\frac{w}{t}\right)^{2} \cdot\left(\frac{f_{y}}{280}\right) \\
& \text { where } \begin{array}{l}
w \\
=\text { larger flat width of the sub element (see Fig. } 8 \text { ) between stiffeners (in } \mathrm{mm} \text { ) } \\
t=\text { thickness of the element }(\mathrm{mm}) \\
\quad t_{u}=\text { yield stress }\left(\mathrm{N} / \mathrm{mm}^{2}\right)
\end{array}
\end{aligned}
$$

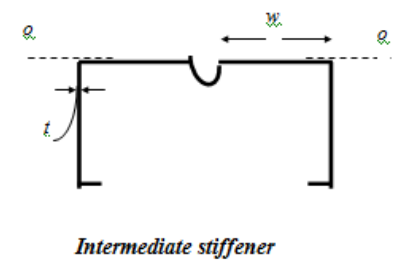

\section{Effective Section Properties}

Since the stress concentrations are very high at edges the resistance of the section strength depends on certain selective parts of the section as shown in Fig. 4

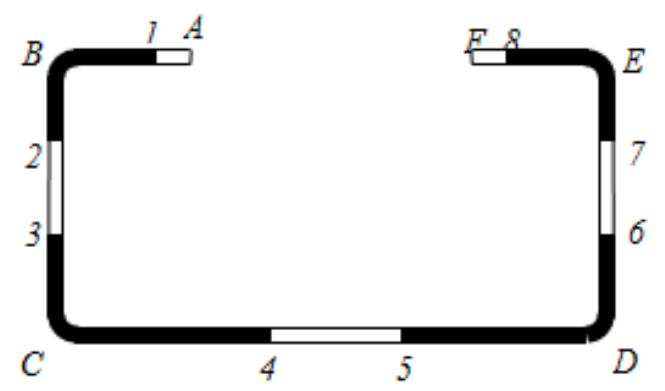

For I-section it is shown in Fig. 5

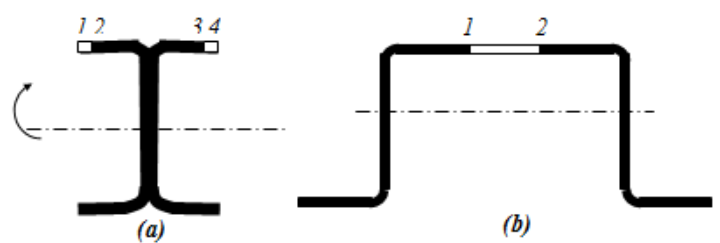

Minimum requirement for a Stiffeners:[16]-19]

With commonly used notations:

$$
I_{\min }=\frac{b^{3} t}{375}
$$

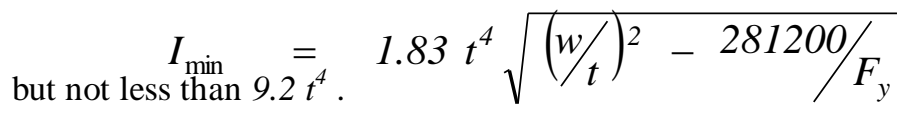

$$
\underset{\text { than } 4.8 t}{d_{\text {min }}}=2.8 t \sqrt[6]{(w / t)^{2}-281208 / f_{y}}
$$

\section{CONCLUSION}

The introduction on the subject of thin walled sections are stated. The concept of plate buckling and post buckling behaviour are explained. The effective width concept in the area of thin walled sections are illustrated. The strength if lip and intermediate stiffeners are explained as per the Indian Standards. 


\section{REFERENCES}

1. Meikandaan T.P., Hemapriya M.,Use of glass FRP sheets as external flexural reinforcement in RCC Beam,International Journal of Civil Engineering and Technology,V-8,I-8,PP-1485-1501,Y-2017

2. Saraswathy R., Saritha B.,Planning of integrated satellite township at Thirumazhisai,International Journal of Applied Engineering Research,V-9,I-22,PP-5558-5560,Y-2014

3. Meikandaan T.P., Ramachandra Murthy A.,Flexural behaviour of RC beam wrapped with GFRP sheets,International Journal of Civil Engineering and Technology,V-8,I-2,PP-452-469,Y-2017

4. Meikandaan T.P., Murthy A.R.,Experimental study on strengthening of rc beams using glass Fiber,International Journal of Civil Engineering and Technology,V-9,I-11,PP-959-965,Y-2018

5. Venkat Raman K., Dayakar P., Raju K.V.B.,An experimental study on effect of cone diameters in penetration test on sandy soil, International Journal of Civil Engineering and Technology,V-8,I-8,PP-1581-1588,Y-2017.

6. Ilayaraja K., Reza W., Kumar V., Paul S., Chowdhary R.,Estimation of land surface temperature of Chennai metropolitan area using Landsat images,International Journal of Civil Engineering and Technology,V-8,I-8,PP-1450-1456,Y-2017

7. Saritha B., Chockalingam M.P.,Photodradation of malachite green DYE using TIO2/activated carbon composite,International Journal of Civil Engineering and Technology,V-8,I-8,PP-156-163,Y-2017

8. Shendge R.B., Chockalingam M.P., Saritha B., Ambica A.,Swat modelling for sediment yield: A case study of Ujjani reservoir in Maharashtra, India,International Journal of Civil Engineering and Technology,V-9,I-1,PP-245-252,Y-2018

9. Chitra R.,Analysis of traffic and management at Kovilambakkam intersection,International Journal of Civil Engineering and Technology,V-8,I-8,PP-1433-1443,Y-2017

10. Saritha B., Ilayaraja K., Eqyaabal Z.,Geo textiles and geo synthetics for soil reinforcement,International Journal of Applied Engineering Research,V-9,I-22,PP-5533-5536,Y-2014

\section{AUTHORS PROFILE}

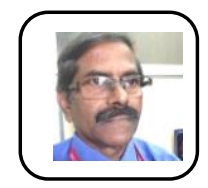

S. J. Mohan, Assistant Professor, Department Of Civil Engineering,,Bharath Institution of Higher Education And Research,TamilNadu, India

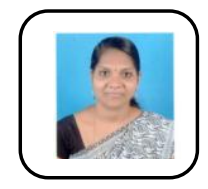

S. Thendral, Assistant Professor,,Department Of Civil Engineering,,Bharath Institution Of Higher Education And Research,TamilNadu, India

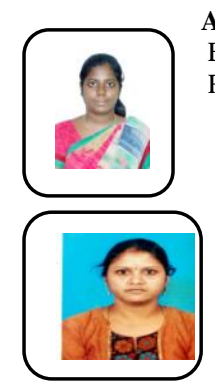

A.Arunya, Asistant Professor, Department Of Civil Engineering,,Bharath Institution of Higher Education And Research,TamilNadu, India

R. Chitra, Asistant Professor, Department Of Civil Engineering,,Bharath Institution of Higher Education And Research,TamilNadu, India 